\title{
Measurement of Specific Heat Capacity Using Differential Scanning Calorimeter
}

\author{
J. E. Daw
}

November 2008

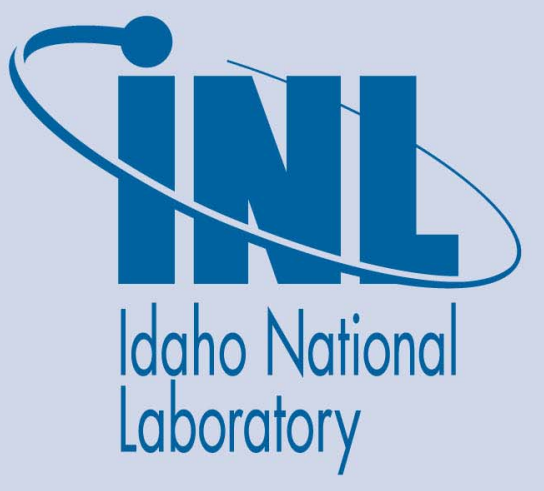

The INL is a U.S. Department of Energy National Laboratory operated by Battelle Energy Alliance 
INL/EXT-08-15056

\title{
Measurement of Specific Heat Capacity Using Differential Scanning Calorimeter
}

\author{
J. E. Daw
}

November 2008

\begin{abstract}
Idaho National Laboratory
Idaho Falls, Idaho 83415
\end{abstract}

http://www.inl.gov

Prepared for the

U.S. Department of Energy

Through the INL LDRD Program

Under DOE Idaho Operations Office

Contract DE-AC07-05ID14517 


\section{CONTENTS}

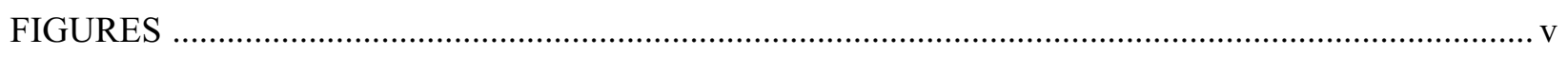

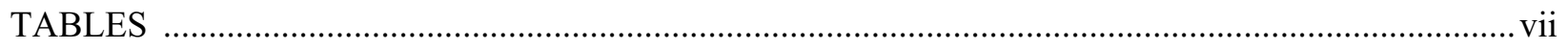

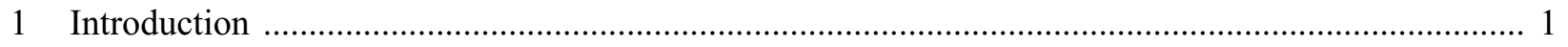

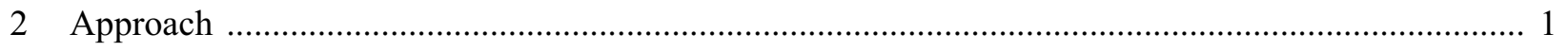

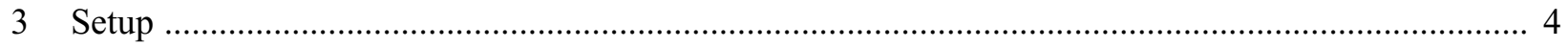

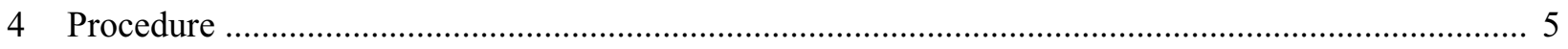

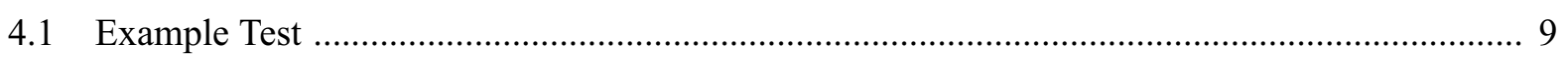




\section{FIGURES}

1. Diagram of heating pattern and system geometry. .................................................................. 1

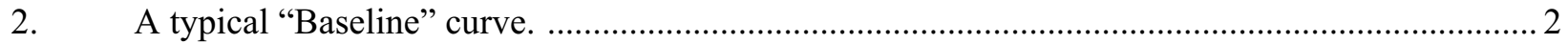

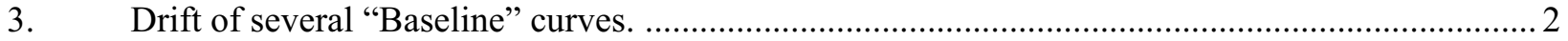

4. Raw data for sapphire reference and "unknown" sample material. ............................................. 3

5. Calculated Cp curves for sapphire and "unknown" samples compared with

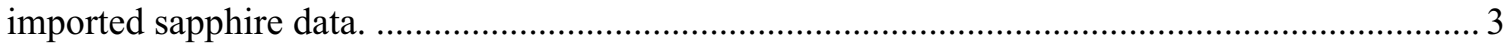

6. Differential Scanning Calorimeter workstation at HTTL. ........................................................ 4

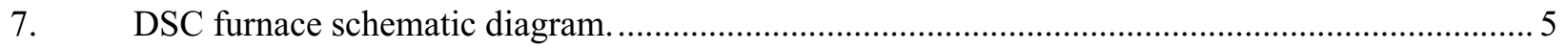

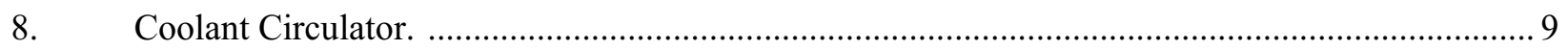

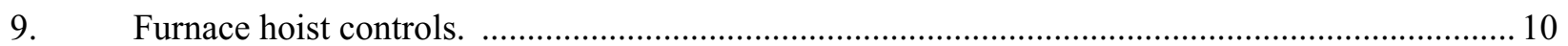

10. Crucibles and sample carrier adjustment micrometers. ......................................................... 11

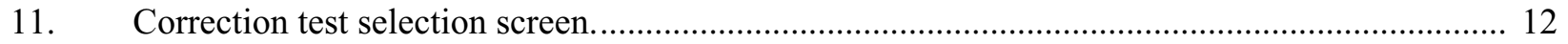

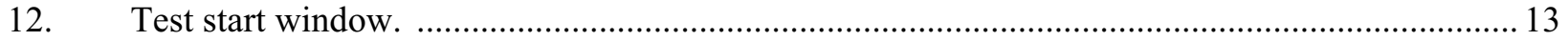

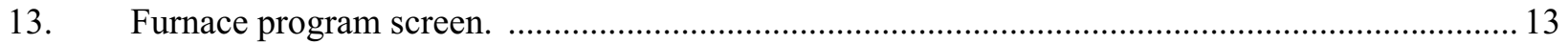

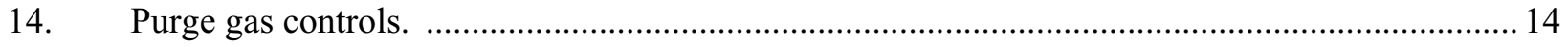

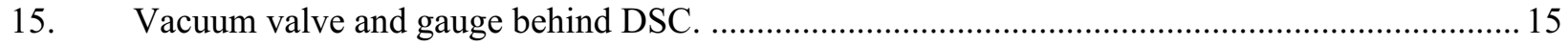

16. Data export options screen with material standard data curve shown and experimental curve highlighted. 


\section{TABLES}

Table 1. Test Procedure. ................................................................................ 5 


\section{Introduction}

This document describes the process used at the Idaho National Laboratory's (INL) High Temperature Test Laboratory (HTTL) for measuring specific heat capacity using a differential scanning calorimeter (DSC). The document is divided into four sections: Approach, in which the technique is described; Setup, in which the physical system is described; Procedure, in which the testing steps are listed and detailed; and Example Test, in which a typical test is outlined following the steps listed in the Procedure section.

\section{Approach}

Specific heat capacity $\left(c_{p}\right)$ is a material property describing the energy required to induce a certain change in the temperature of a unit mass of the material. To measure this quantity, a differential scanning calorimeter (DSC) may be used. The DSC measures specific heat capacity by heating a sample and measuring the temperature difference between the sample and a reference. The test setup is shown in Figure 1. Reference and sample crucibles are placed on a sample carrier within a furnace of cylindric geometry which generates heat radially toward the center. Temperature is detected by thermocouples in contact with each crucible. One thermoelement is shared between the crucibles (as seen in the Side Furnace View) allowing the temperature difference to be measured as a voltage. Three measurements are necessary for calculating specific heat. First a "Baseline" is recorded. This is the response with both crucibles empty, yielding a signal bias inherent in the system. Next is a reference test, in which a sample with a well defined specific heat is tested for comparison to an experimental sample. Finally, an experimental sample is tested. The "Baseline" allows removal of system bias from the data, while the reference test allows calculation of the specific heat of the experimental sample as a ratio of the reference material specific heat.

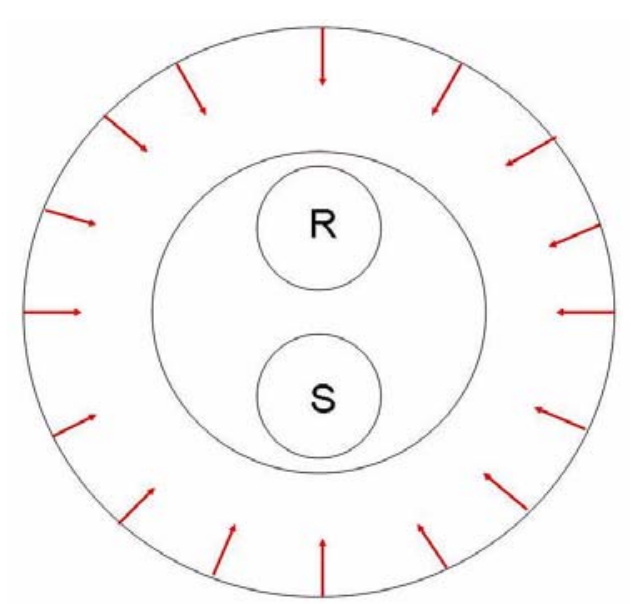

Top Furnace View

$(\mathrm{R}=$ Reference, $\mathrm{S}=$ Sample $)$

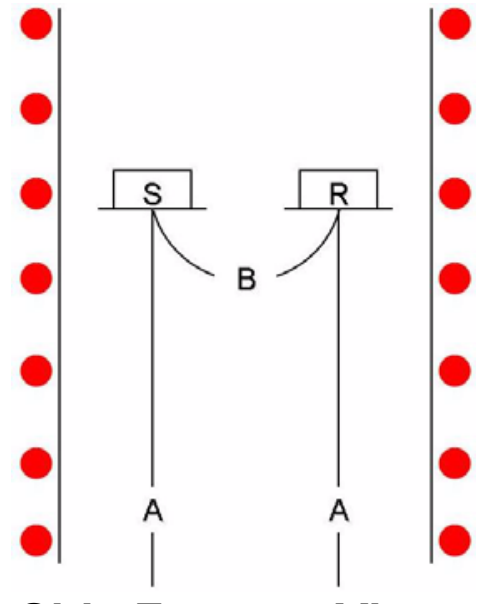

Side Furnace View

(Heating Elements In Red)

Figure 1. Diagram of heating pattern and system geometry. 
As described previously, all DSC tests are performed as "triples." For each test sample, three tests must be performed. The first test is a "Baseline." The "Baseline" test records system characteristics and (assuming the baseline is relatively consistent from test to test) allows removal of the system bias from experimental data. "Baseline" tests must be run before any samples can be tested. The "Baseline" should be compared to other recent "Baselines" to make sure the system is running consistently. If the "Baselines" begin to drift (deviating by more than 0.2 microvolts from a previous test or exhibiting more than 2.5 microvolts in signal variance during a test), the sample holder position should be adjusted. While adjusting the sample holder position, several "Baseline" tests should be performed to demonstrate consistency of the new sample holder position. Figure 2 displays a typical "Baseline" curve with temperature displayed as a function of time.

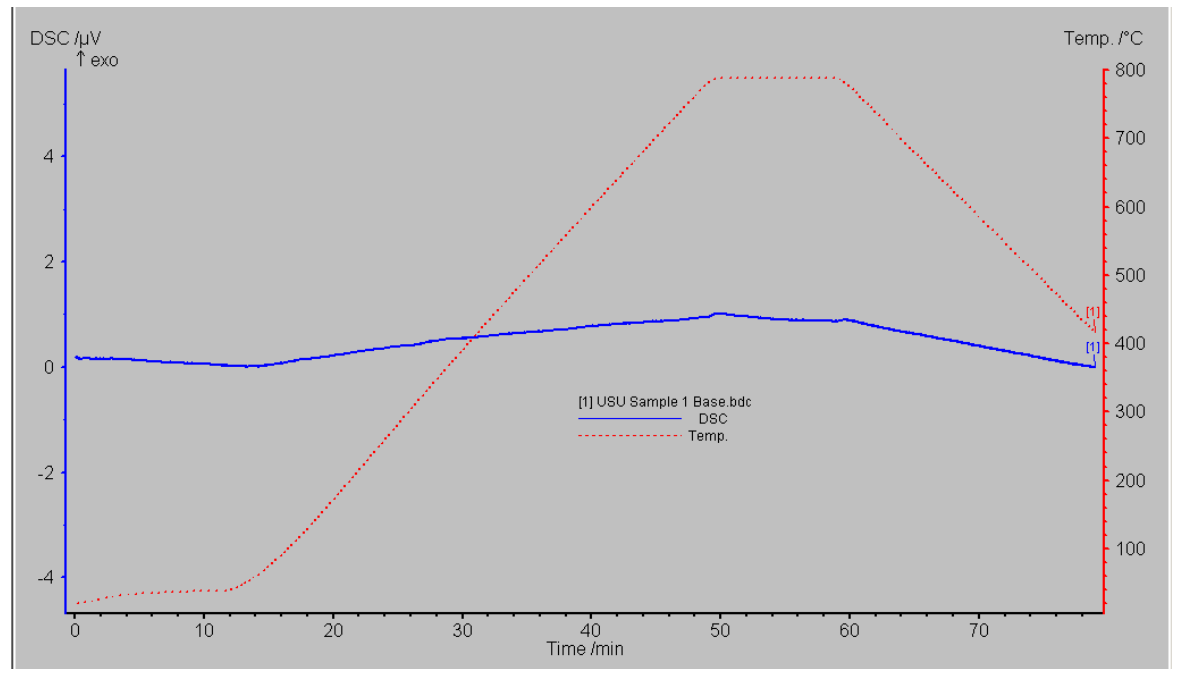

Figure 2. A typical "Baseline" curve.

Figure 3 shows several "Baseline" curves with notable drift from curve to curve.

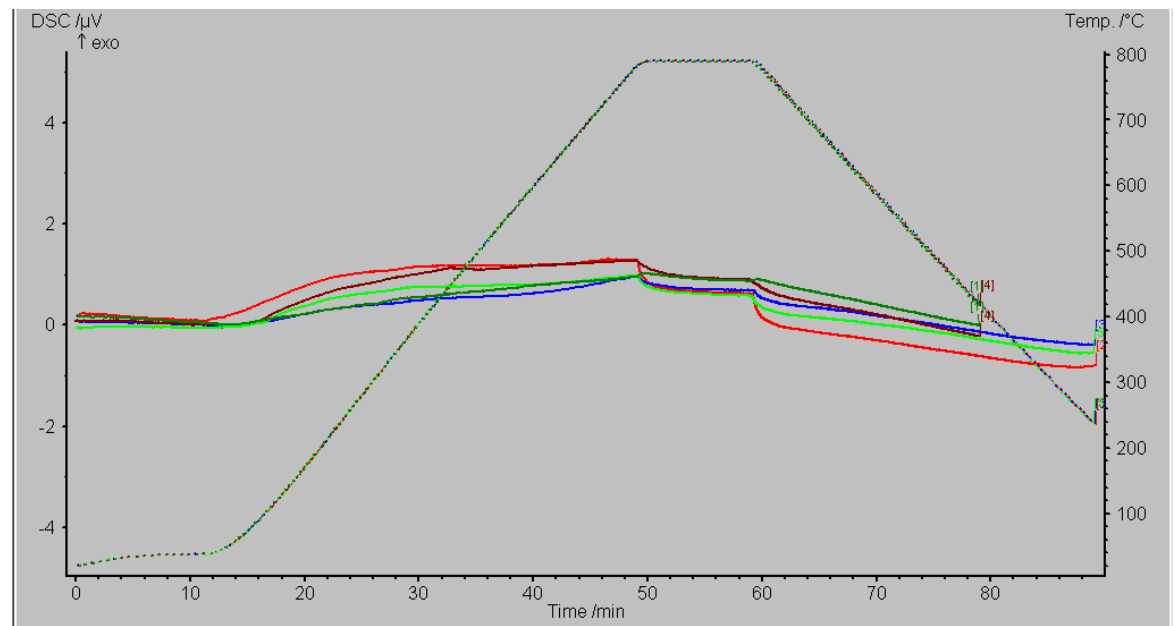

Figure 3. Drift of several "Baseline" curves. 
After a repeatable "Baseline" has been recorded, a reference material must be tested (procedure described in section 4). This reference (the second part of the "triple") must be one of the Netzsch supplied samples, with a well defined curve pre-loaded into the software. The reference curve will use the same program as the "Baseline" and is started by opening the "Baseline" file. The experimental sample (the third test in the "triple") is tested in exactly the same way as the reference. Figure 4 shows representative reference and sample material curves.

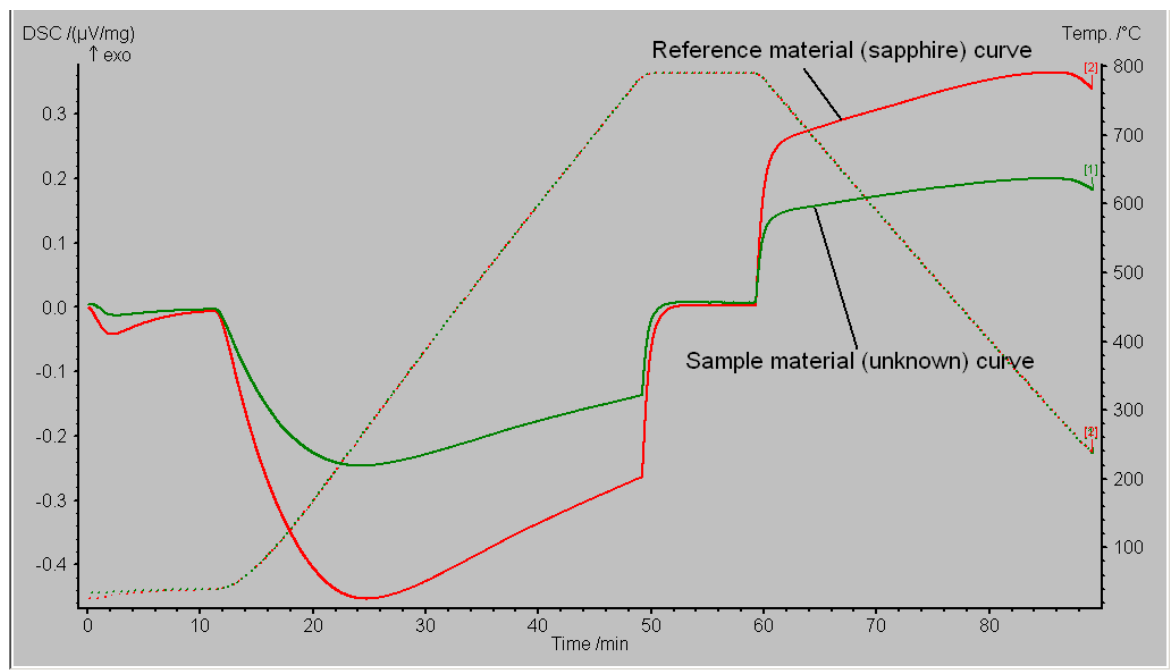

Figure 4. Raw data for sapphire reference and "unknown" sample material.

After using the ratio method to determine $\mathrm{c}_{\mathrm{p}}$, the true value of a standard material may be imported for comparison. In this way confidence may be gained in the results of testing. Figure 5 shows the imported standard curve for sapphire, as well as experimentally derived curves for sapphire and the "unknown" sample from Figure 4.

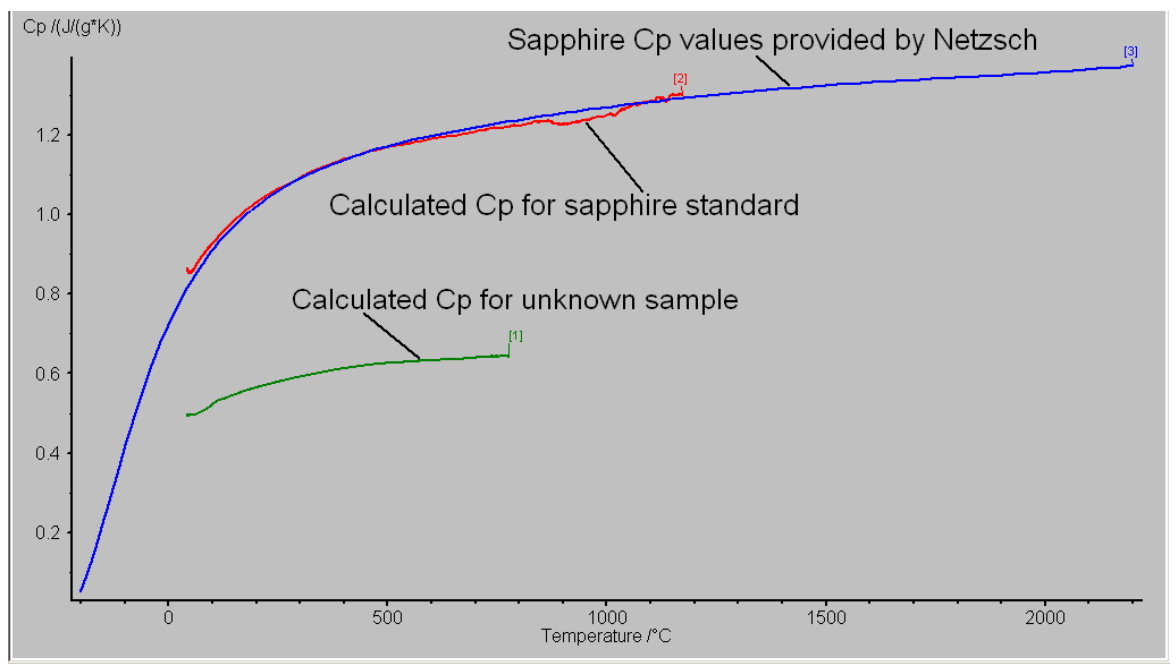

Figure 5. Calculated $\mathrm{Cp}$ curves for sapphire and "unknown" samples compared with imported sapphire data. 


\section{Setup}

Figure 6 shows the Netzsch 404 Differential Scanning Calorimeter installed at Idaho National Laboratory's (INL) High Temperature Test Laboratory (HTTL). The system consists of the DSC 404 (containing the furnace, hoist, and sample holder), the Thermal Analysis System Controller (TASC) 414/4 (which links the calorimeter hardware to the measurement software), the furnace power source, the coolant system, the vacuum pump (for evacuating oxidizing gases), and the CPU (for recording and processing data). The Netzsch DSC 404 system is supplied with two separate software packages. First is the DSC 404C Measurement package. This program allows data logging of furnace temperature and differential sample temperature data as well as temperature control programming. Second is the Proteus Analysis package which allows data correction, analysis, and comparison. Also shown in Figure 6 is the Netzsch 402 DIL push-rod dilatometer installed at the HTTL(INL/EXT-07-13120). The dilatometer is placed in close proximity to the DSC because the TASC, CPU, Furnace Power Source, and Coolant System (not shown) must be interchanged between the systems.

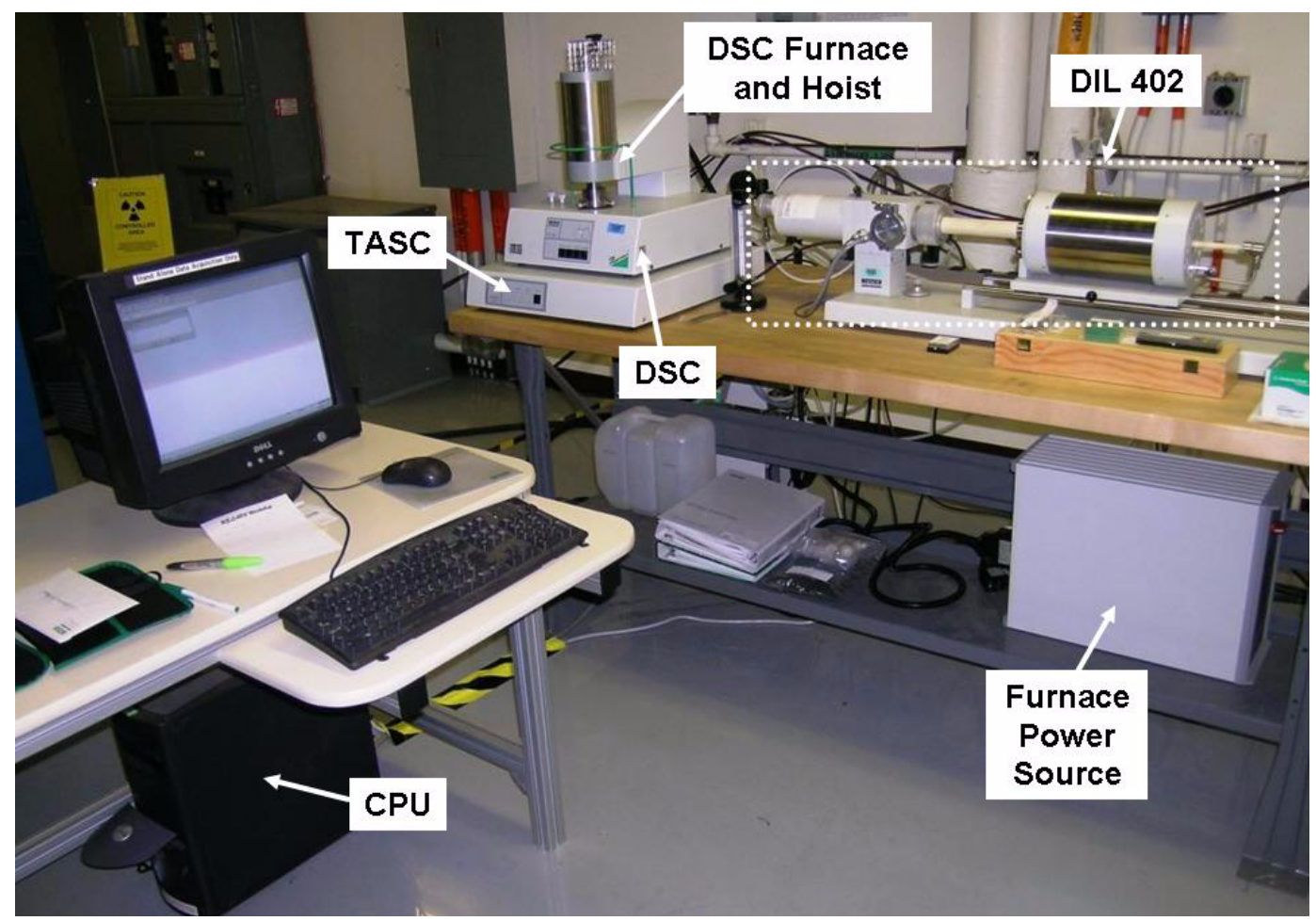

Figure 6. Differential Scanning Calorimeter workstation at HTTL.

Figure 7 shows a schematic of the furnace/hoist system seen in Figure 6. 


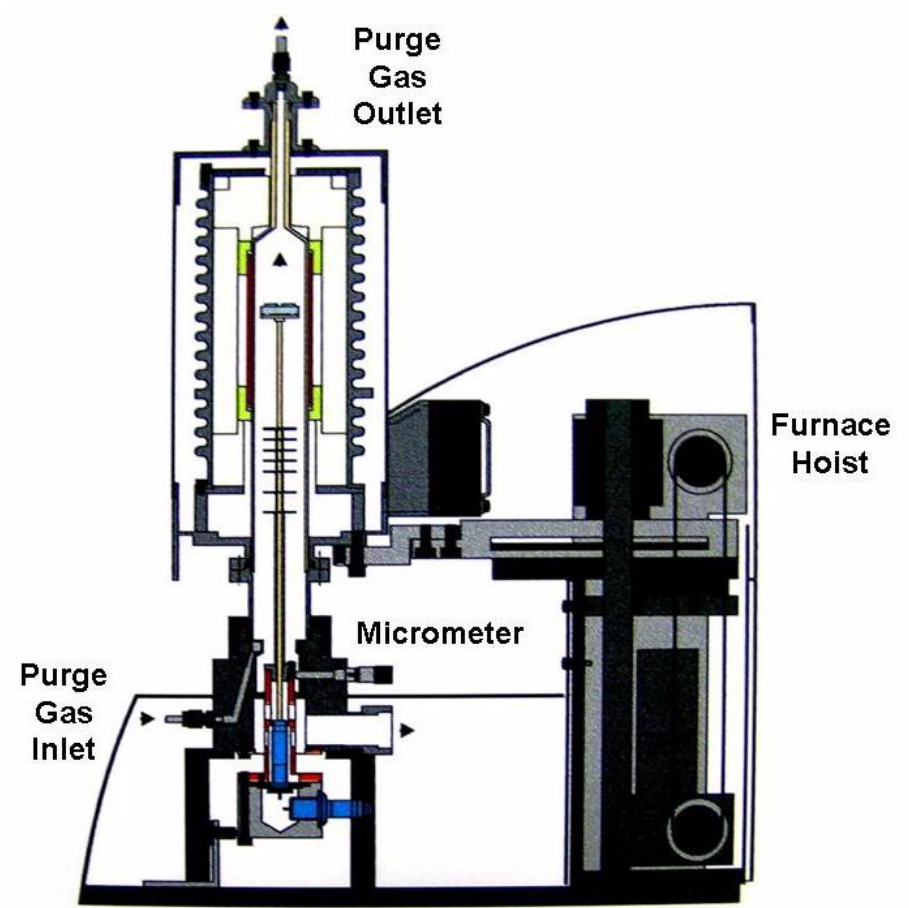

Figure 7. DSC furnace schematic diagram.

\section{Procedure}

Table 1 details the test procedure used.

Table 1. Test Procedure.

\begin{tabular}{|c|c|c|c|c|c|}
\hline & Ste & Action & Process & Purpose & Comments \\
\hline \multirow{6}{*}{$\begin{array}{l}\text { Prepare } \\
\text { System }\end{array}$} & 1 & $\begin{array}{l}\text { Start Coolant } \\
\text { Flow }\end{array}$ & $\begin{array}{c}\text { Press Both Toggle } \\
\text { Switches To On Position } \\
\text { And Press On/Off Button } \\
\text { On Keypad }\end{array}$ & & \\
\hline & 2 & $\begin{array}{l}\text { Start Purge } \\
\text { Gas }\end{array}$ & $\begin{array}{c}\text { Open Valve On Argon } \\
\text { Cylinder }\end{array}$ & & $\begin{array}{c}\text { Purge Gas Will Need To Be Started } \\
\text { Later Using The Software }\end{array}$ \\
\hline & 3 & \begin{tabular}{|c|} 
Turn On \\
Furnace \\
Power Source
\end{tabular} & $\begin{array}{c}\text { Turn Red Switch On } \\
\text { Furnace Power Source To } \\
\text { On Position }\end{array}$ & & \\
\hline & 4 & $\begin{array}{l}\text { Turn On } \\
\text { TASC }\end{array}$ & $\begin{array}{c}\text { Select On Using Toggle } \\
\text { Switch On Back Of TASC }\end{array}$ & & \\
\hline & 5 & Turn On DSC & $\begin{array}{l}\text { Select On Using Toggle } \\
\text { Switch On Back Of DSC }\end{array}$ & & \\
\hline & 6 & Start CPU & $\begin{array}{c}\text { Press Button On Front Of } \\
\text { CPU }\end{array}$ & & \\
\hline
\end{tabular}


Table 1. Test Procedure.

\begin{tabular}{|c|c|c|c|c|}
\hline & 7 & Clean Sample & & \\
\hline & 8 & $\begin{array}{c}\text { Measure } \\
\text { Sample Mass }\end{array}$ & & \\
\hline & 9 & Open Furnace & $\begin{array}{l}\text { Press Safety Button On } \\
\text { Side Of DSC and Up } \\
\text { Button On Front Of DSC } \\
\text { Simultaneously }\end{array}$ & \\
\hline & 10 & $\begin{array}{l}\text { Loosen } \\
\text { Crucibles }\end{array}$ & $\begin{array}{c}\text { Using Tweezers, Gently } \\
\text { Rock Crucibles Back And } \\
\text { Forth Until They Come } \\
\text { Free }\end{array}$ & $\begin{array}{c}\text { Not Necessary If Crucibles Are Not } \\
\text { Loaded }\end{array}$ \\
\hline $\begin{array}{l}\text { Prepare } \\
\text { Sample }\end{array}$ & 11 & $\begin{array}{l}\text { Remove } \\
\text { Sample } \\
\text { Crucible }\end{array}$ & $\begin{array}{l}\text { Using Tweezers, Gently } \\
\text { Lift Crucible From Holder } \\
\text { And Set On Flat Surface }\end{array}$ & $\begin{array}{c}\text { Sample Crucible Is Nearest Front of } \\
\text { DSC. Tip Crucible Over to Remove } \\
\text { Lid And Sample. Do Not Rotate } \\
\text { Crucible! }\end{array}$ \\
\hline & 12 & Load Sample & $\begin{array}{c}\text { Using Tweezers, Drop } \\
\text { Sample Into Crucible And } \\
\text { Gently Shake Crucible To } \\
\text { Center Sample, Replace } \\
\text { Lid }\end{array}$ & \\
\hline & 13 & $\begin{array}{l}\text { Replace } \\
\text { Crucible In } \\
\text { Sample } \\
\text { Holder }\end{array}$ & $\begin{array}{c}\text { Using Tweezers, Place } \\
\text { Crucible Back Into Sample } \\
\text { Holder }\end{array}$ & $\begin{array}{c}\text { Crucibles Should Be In Same } \\
\text { Orientation And Position As Before } \\
\text { Removal. Lids Should Be In Same } \\
\text { Orientation. Tap Each Lid (Front } \\
\text { Then Back) To Maintain Sample } \\
\text { Holder Position Consistency. }\end{array}$ \\
\hline & 14 & Close Furnace & $\begin{array}{l}\text { Press The Safety And } \\
\text { Down Buttons } \\
\text { Simultaneously }\end{array}$ & $\begin{array}{c}\text { As Furnace Nears Sample Holder, } \\
\text { Slowly Lower Furnace Making Sure } \\
\text { Furnace Will Not Contact Sample } \\
\text { Holder }\end{array}$ \\
\hline
\end{tabular}


Table 1. Test Procedure.

\begin{tabular}{|c|c|c|c|c|c|}
\hline \multirow{13}{*}{$\begin{array}{c}\text { Prepare } \\
\text { Test }\end{array}$} & & 15 & \begin{tabular}{|c|} 
Open DSC \\
404 Software
\end{tabular} & $\begin{array}{l}\text { Double Click Icon On } \\
\text { Computer Desktop }\end{array}$ & \\
\hline & $\begin{array}{c}\text { Correction } \\
\text { Test }\end{array}$ & $16 \mathbf{a}$ & $\begin{array}{l}\text { Open New } \\
\text { "Correction" } \\
\text { File }\end{array}$ & $\begin{array}{c}\text { Click "New" Under "File," } \\
\text { Select "Correction," Enter } \\
\text { Data }\end{array}$ & $\begin{array}{c}\text { Sample And Reference Crucibles } \\
\text { Are Empty }\end{array}$ \\
\hline & & $17 \mathbf{a}$ & Program Test & Follow Steps & $\begin{array}{l}\text { Select "TcalZero," "SensZero," } \\
\text { Program Furnace Steps }\end{array}$ \\
\hline & $\begin{array}{c}\text { Sample + } \\
\text { Correction } \\
\text { Test }\end{array}$ & $16 \mathrm{~b}$, & $\begin{array}{l}\text { Open "Sample } \\
+ \text { Correction" } \\
\text { Test }\end{array}$ & $\begin{array}{l}\text { Click "Open" Under } \\
\text { "File," Choose } \\
\text { "Correction" file, Select } \\
\text { "Sample +Correction," } \\
\text { Follow Steps }\end{array}$ & $\begin{array}{l}\text { Program Will Be Same As For } \\
\text { "Correction" Test, } \\
\text { "Sample+Correction" Is Used For } \\
\text { Standard And Sample Tests }\end{array}$ \\
\hline & & 18 & $\begin{array}{l}\text { Start Gas } \\
\text { Flow }\end{array}$ & $\begin{array}{l}\text { Under "Diagnosis" Select } \\
\text { "Gases And Switches," } \\
\text { Select "Purge 1" }\end{array}$ & $\begin{array}{c}\text { Purge Prior To Starting Test } \\
\text { Program, Allow Argon To Flow For } \\
\text { Several Minutes }\end{array}$ \\
\hline & & 19 & $\begin{array}{l}\text { Stop Gas } \\
\text { Flow }\end{array}$ & Select "Purge 1" & \\
\hline & & 20 & \begin{tabular}{|c|} 
Close Exit \\
Valve At Top \\
Of Furnace
\end{tabular} & Turn Valve 90 Degrees & $\begin{array}{c}\text { Close Valve Immediately After } \\
\text { Stopping Gas Flow }\end{array}$ \\
\hline & & 21 & $\begin{array}{l}\text { Start Vacuum } \\
\text { Purge }\end{array}$ & \begin{tabular}{|} 
Start Pump By Switching \\
Toggle Switch To On \\
Position, Slowly Open \\
Vacuum Valve At Back Of \\
DSC By Turning \\
Counterclockwise
\end{tabular} & $\begin{array}{l}\text { Vacuum Purge Must Be Slow To } \\
\text { Avoid Moving Crucibles Or Lids, } \\
\text { Allow Vacuum Purge To Continue } \\
\text { Until Gauge Needle Stops Moving }\end{array}$ \\
\hline & & 22 & $\begin{array}{c}\text { Close Vacuum } \\
\text { Valve }\end{array}$ & $\begin{array}{l}\text { Turn Valve Knob } \\
\text { Clockwise }\end{array}$ & \\
\hline & & 23 & $\begin{array}{l}\text { Start Gas } \\
\text { Flow }\end{array}$ & Select "Purge 1" & $\begin{array}{l}\text { Refill Furnace With Argon Until } \\
\text { Atmospheric Pressure Is Reached }\end{array}$ \\
\hline & & 24 & \begin{tabular}{|c|} 
Open Exit \\
Valve At Top \\
Of Furnace
\end{tabular} & $\begin{array}{c}\text { Turn Valve Back To Open } \\
\text { Position }\end{array}$ & $\begin{array}{c}\text { Pressure Must Be At Or Just Over } \\
\text { Atmospheric (Zero On Gauge) }\end{array}$ \\
\hline & & 25 & $\begin{array}{l}\text { Continue } \\
\text { Purge }\end{array}$ & $\begin{array}{l}\text { Repeat Steps } 19 \text { Through } \\
24\end{array}$ & $\begin{array}{l}\text { Turn Off Vacuum Pump After Purge } \\
\text { Is Complete }\end{array}$ \\
\hline & & 26 & Start Test & $\begin{array}{l}\text { Press "Start" Button In } \\
\text { Program }\end{array}$ & Test Will Run Automatically \\
\hline
\end{tabular}


Table 1. Test Procedure.

\begin{tabular}{|c|c|c|c|c|c|}
\hline & \begin{tabular}{|c|} 
Analyze \\
Correction \\
File
\end{tabular} & $27 \mathbf{a}$ & $\begin{array}{c}\text { Check } \\
\text { Baseline }\end{array}$ & $\begin{array}{c}\text { Open Baseline } \\
\text { ("Correction") File In } \\
\text { Proteus Program And } \\
\text { Compare To Previous } \\
\text { Baselines }\end{array}$ & $\begin{array}{c}\text { If Baseline Is Within 0.2 Microvolts } \\
\text { Of Previous Acceptable Baselines } \\
\text { And Shows Deviation Of Less Than } \\
2.5 \text { Microvolts Over Test It Is } \\
\text { Acceptable }\end{array}$ \\
\hline $\begin{array}{c}\text { Analyze } \\
\text { Data }\end{array}$ & \begin{tabular}{|c|} 
Analyze \\
Sample+ \\
Correction \\
File
\end{tabular} & $27 \mathbf{b}$ & Calculate $\mathrm{C}_{\mathrm{p}}$ & $\begin{array}{c}\text { Open Both "Sample + } \\
\text { Correction" Files. } \\
\text { Highlight Sample Curve. } \\
\text { Click "Ratio Method" } \\
\text { Under "Measurement." } \\
\text { Choose Standard Curve As } \\
\text { Reference. Select } \\
\text { Appropriate Standard } \\
\text { Material File. }\end{array}$ & $\begin{array}{l}\text { Select The Heating Segment Using } \\
\text { "Settings"=>"Segments", Click } \\
\text { Checked Boxes Of Extraneous } \\
\text { Segments To Deselect Them }\end{array}$ \\
\hline & & $28 b$ & $\begin{array}{l}\text { Compare To } \\
\text { Standard }\end{array}$ & \begin{tabular}{|c|} 
Select "File"=>"Import \\
Standards"=>"Cp." Open \\
Desired Standard File
\end{tabular} & \\
\hline & & 29 & Export Data & $\begin{array}{c}\text { Select Curve, Select } \\
\text { "Extras"=>"Export To } \\
\text { File," Choose Appropriate } \\
\text { Options }\end{array}$ & \\
\hline & & $\mathbf{3 0}$ & $\begin{array}{l}\text { Remove } \\
\text { Samples }\end{array}$ & $\begin{array}{c}\text { If Necessary Open } \\
\text { Furnace, Remove Sample } \\
\text { Crucible, Remove Sample } \\
\text { By Turning Crucible } \\
\text { Upside Down, Replace } \\
\text { Crucible And Lid, Close } \\
\text { Furnace }\end{array}$ & Only When Cooled Sufficiently \\
\hline \multirow{7}{*}{$\begin{array}{l}\text { Shut } \\
\text { Down }\end{array}$} & & 31 & Exit Programs & Close Program Windows & \\
\hline & & 32 & Turn Off CPU & Shut Down Computer & \\
\hline & & 33 & Turn Off DSC & $\begin{array}{c}\text { Switch Toggle On Back Of } \\
\text { DSC To Off Position }\end{array}$ & \\
\hline & & 34 & $\begin{array}{l}\text { Turn Off } \\
\text { TASC }\end{array}$ & $\begin{array}{c}\text { Switch Toggle On Back Of } \\
\text { TASC To Off Position }\end{array}$ & \\
\hline & & 35 & \begin{tabular}{|c|} 
Turn Off \\
Furnace \\
Power Source \\
\end{tabular} & Turn Knob To Off Position & \\
\hline & & 36 & $\begin{array}{c}\text { Turn Off Gas } \\
\text { Flow }\end{array}$ & $\begin{array}{l}\text { Close Valve On Argon } \\
\text { Cylinder }\end{array}$ & \\
\hline & & 37 & $\begin{array}{l}\text { Turn Off } \\
\text { Coolant }\end{array}$ & $\begin{array}{l}\text { Press On/Off Key On } \\
\text { Touch pad, Switch Both } \\
\text { Toggle Controls To Off } \\
\text { Position }\end{array}$ & \\
\hline
\end{tabular}




\subsection{Example Test}

This section details an example test for the purpose of clarifying the testing process. The section will follow the procedure outlined in Table 1.

Step 1: To start coolant flow, set both toggle switches to the "On" position. The display will read "OFF" when the system is ready to activate. Press the "I/O" button on the key pad to start the circulator (Figure 8).

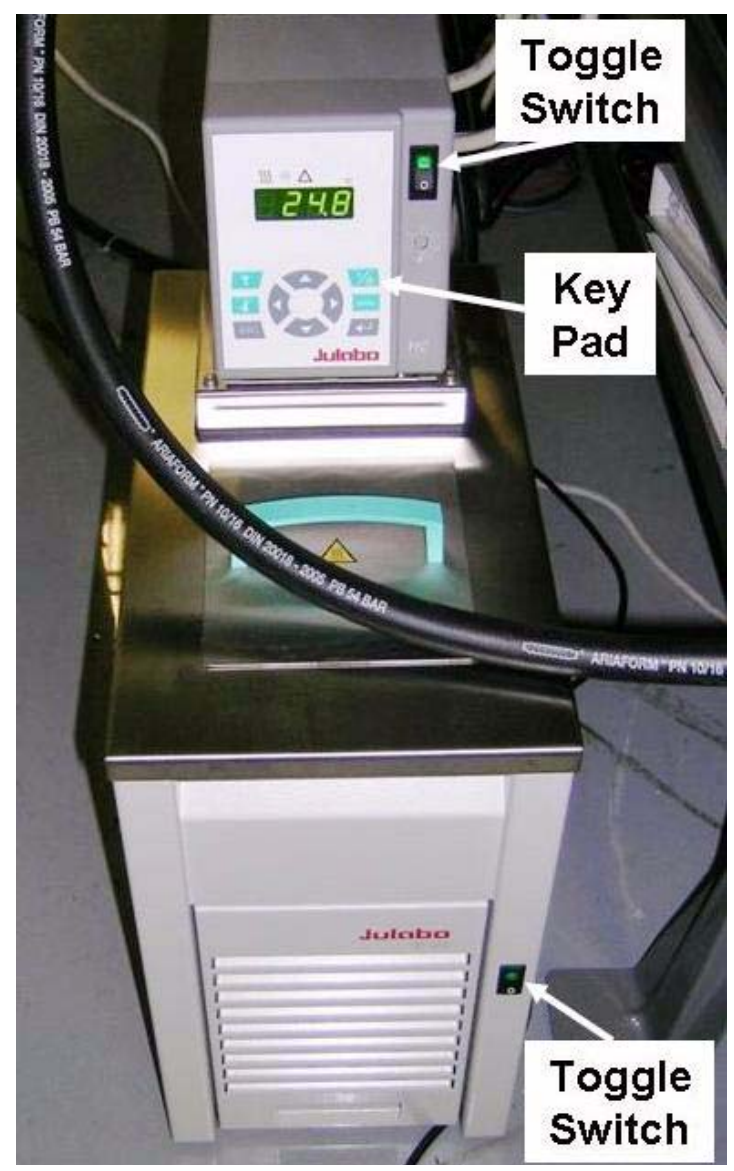

Figure 8. Coolant Circulator

Step 2: Make the purge gas available to the system by opening the flow valve on the purge gas cylinder. This requires that a cylinder be connected to the system.

Step 3: Turn on the furnace power source, shown in Figure 2, by turning the red switch to the "On" position.

Steps 4 and 5: Activate the DSC and TASC, shown in Figure 2, by switching the toggle switches on the back of each device to the "On" position. 
Step 6: Turn on the CPU, shown in Figure 2, by pressing the button on the front of the CPU.

Step 7: Clean sample as required using acetone or alcohol. Liquid cleaning solutions may be inappropriate for porous samples. After cleaning, the sample should only be handled with forceps or gloved hands.

Step 8: The sample mass must be measured, in milligrams.

Step 9: Open the furnace by simultaneously pressing both the up (denoted by an upward pointing arrow) and "Safety" buttons (as depicted in Figure 9).
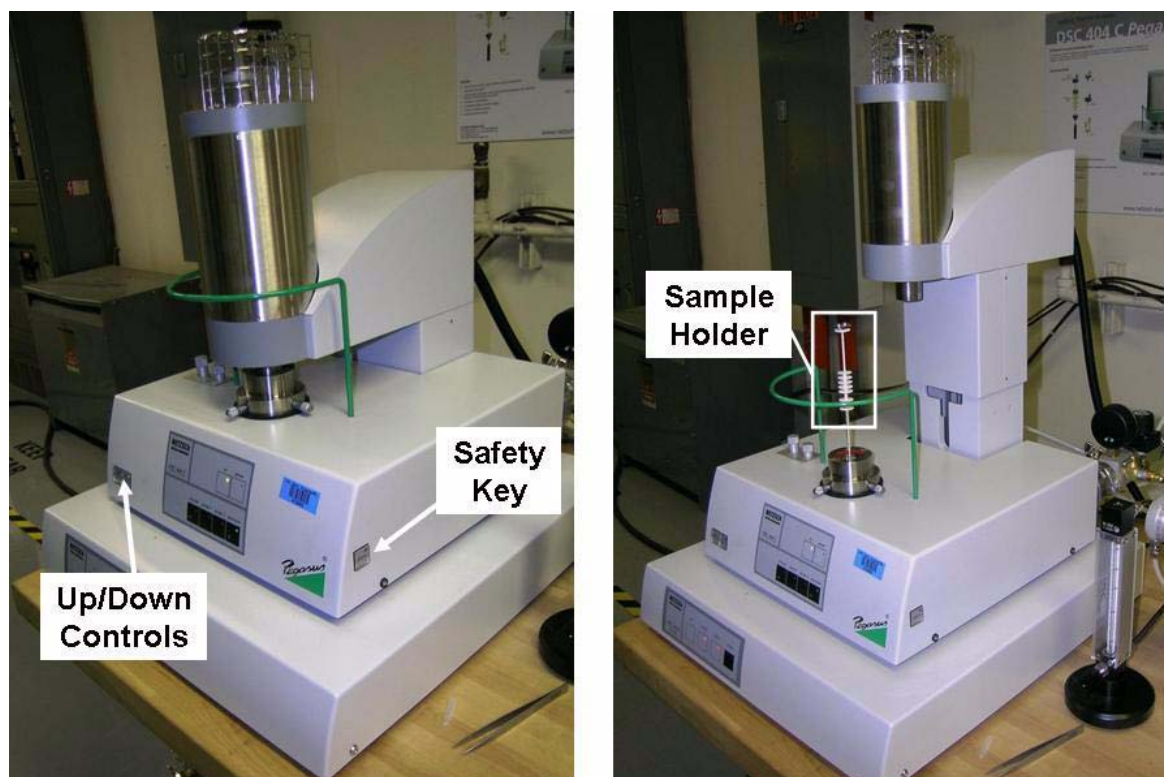

Figure 9. Furnace hoist controls.

Step 10: At high temperatures, the crucibles may become weakly bonded to the sample carrier (if using the platinum crucibles). If a test has been run previously, the crucibles must be loosened. This is accomplished by lightly grasping the crucibles (one at a time) with forceps and gently rocking the crucibles back and forth until they loosen. The crucibles and sample carrier adjustment micrometers are shown in Figure 10. 


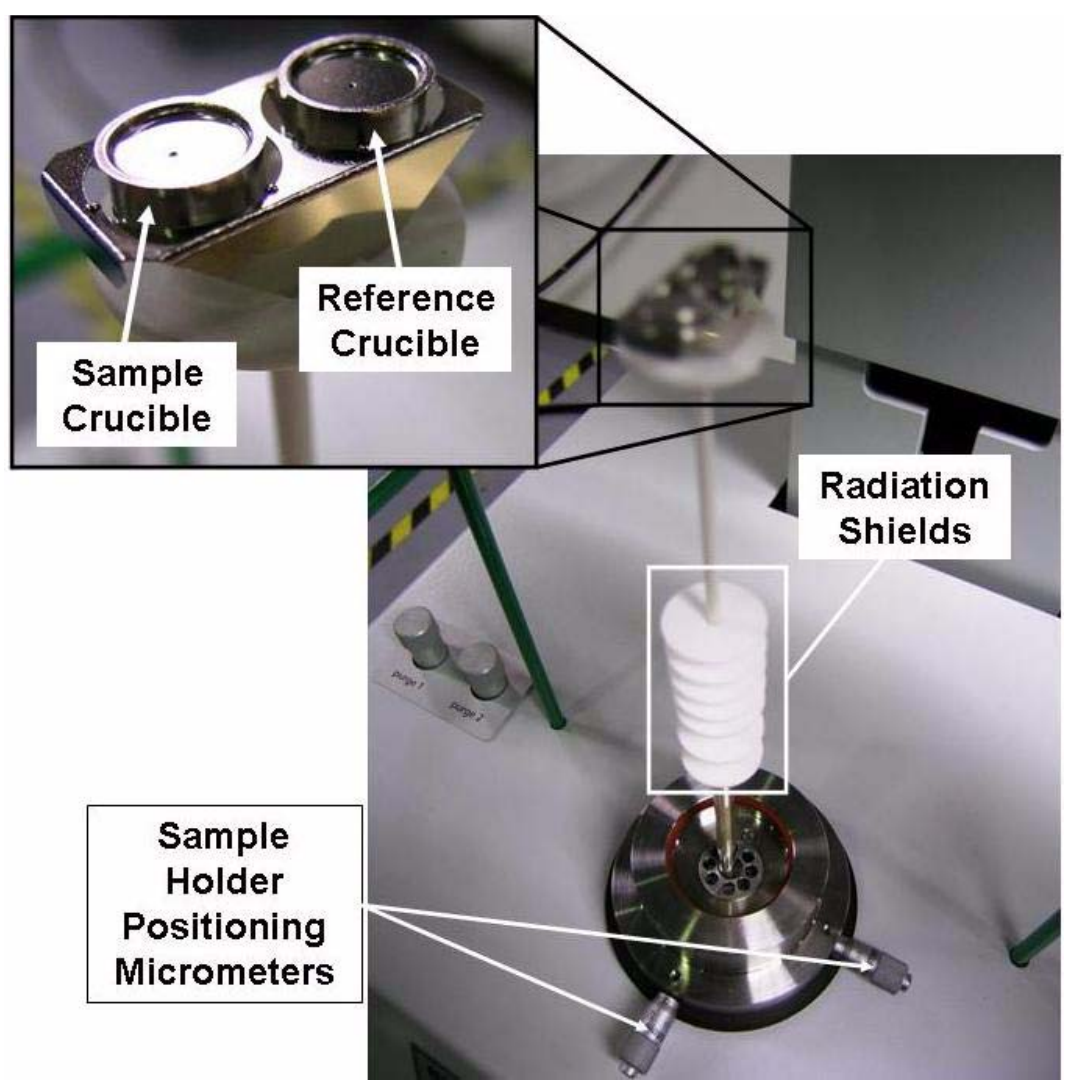

Figure 10. Crucibles and sample carrier adjustment micrometers.

Step 11: If there is a sample in the "sample" crucible, it must be remove prior to running a new baseline test. Using forceps, gently grasp the "sample" crucible and lift it off the sample carrier. Maintaining the orientation of the crucible, invert the crucible over a flat surface to remove the lid and sample. Still maintaining orientation, set the crucible down open side up.

Step 12: If necessary, place a new sample in the crucible and gently shake the crucible to center the sample. Replace the lid keeping the orientation of the lid as close as possible to what it was before removal from the sample carrier.

Step 13: Maintaining orientation, place the crucible gently back into the sample carrier. The crucible should sit flat, and the lid should be level with the lid of the reference crucible. Both crucibles should be placed to the back of their carrier locations. This position is not critical, but consistency in positioning is. The lids should be tapped, very lightly, with forceps. The sample crucible is tapped first, and then the reference crucible. As the sample carrier ages it will become less stable. Tapping the crucibles, in order, will help keep the position of the carrier constant.

Step 14: Close the furnace by pressing the down (denoted with a downward pointing arrow) and the "Safety" buttons simultaneously. Move the carrier in small increments as the leading edge passes the sample carrier to ensure that there is no contact. 
Step 15: Double click the DSC 404 icon on the computer desktop to open the dilatometer control software.

Step 16a: Open a new "Correction" (baseline) file by selecting "File" from the toolbar and clicking "New." When the screen shown in Figure 11 appears, select "Correction" and fill in the appropriate information. Be aware that the reference will always be empty and that the crucible masses are always set to zero. Click "Continue" when the information has been entered.

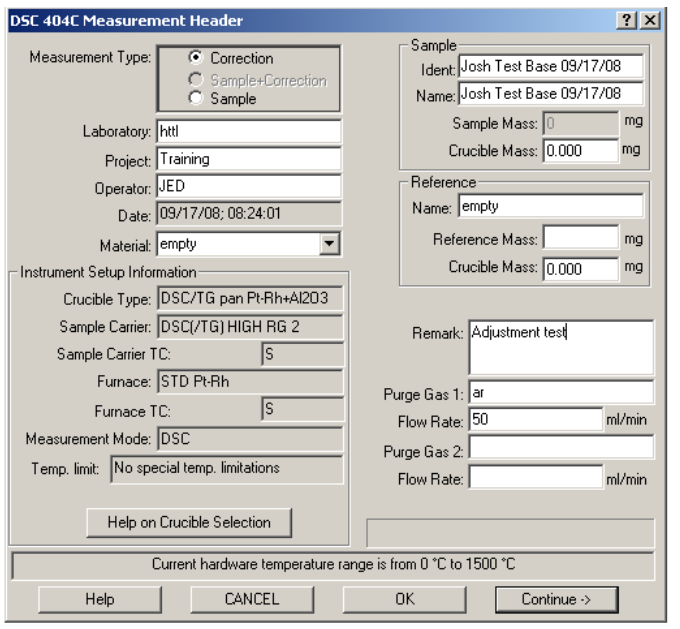

Figure 11. Correction test selection screen.

Step 17a: Program the furnace steps using the screen shown in Figure 12. First, a starting temperature is entered under "Category." This temperature should be slightly higher than the maximum expected ambient temperature. Purge gases and sample temperature control (STC) may also be selected for each temperature step. STC controls the furnace by reading the sample temperature instead of the furnace temperature. STC is not generally used. Next click "Add" to add another step. "Add" must be clicked after the addition of each step. Dynamic steps allow the addition of a temperature rise or drop. If a dynamic step is added, final temperature and ramp rate must also be selected under "Category." Isothermal segments allow the temperature to equalize between dynamic steps. A duration must be programmed under "Category" if an isotherm is added. Once all temperature steps are programmed, select "Final." An emergency temperature limit will be added. This temperature should be about $25^{\circ} \mathrm{C}$ over the maximum test temperature and will shut down the system if reached. Click "Add" to activate the "Continue" button, and click when the program is ready. 


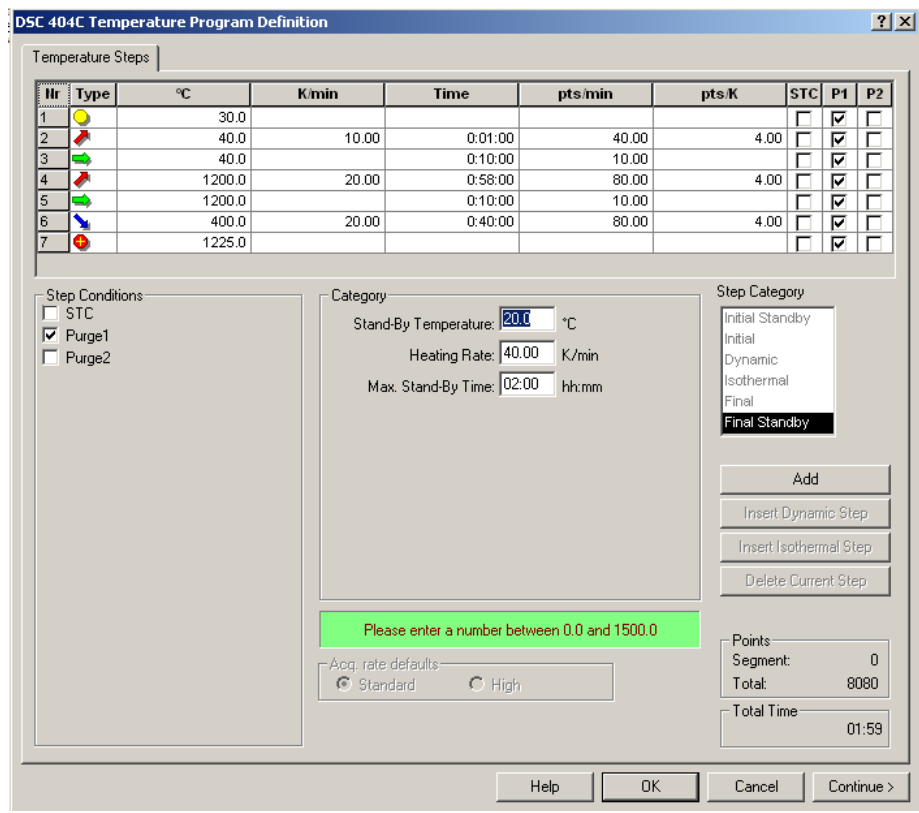

Figure 12. Furnace program screen.

Step 16b: To test a sample, three test runs must be completed. The first is a baseline test, or "Correction", as was described above. The second test is run on a standard, supplied by the manufacturer. For this test "Sample + Correction" is selected when the screen in Figure 11 appears. For this test, a sample mass must be entered. The third test is run on the experimental sample. The test is run exactly as for the manufacturer supplied standard (but should be named differently). $\mathrm{C}_{\mathrm{p}}$ will be calculated based on the signal ratio of the two samples, therefore it is very important to select reference and sample masses that are similar (within 2-3 milligrams).

Step 17b: The "Sample + Correction" test will be linked to a corresponding "Correction" run. This means that the temperature program is already set. "TcalZero" and "SensZero" must be selected again if they were used in the baseline test.

Steps 18-20: When the test is ready to start, the window shown in Figure 13 will be displayed.

Figure 13. Test start window.

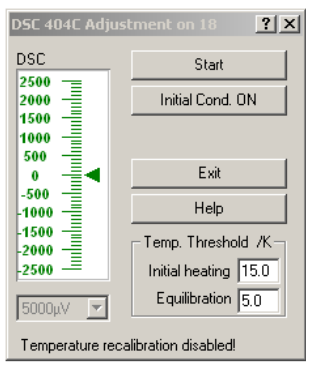


Before starting the test, the furnace chamber must be purged. On the toolbar, select "Diagnosis." Click "Gases and Switches." If a purge gas is flowing, the box next to the purge gas number will be checked. If there is no flow, check the appropriate box to start flow. Let the gas flow for several minutes. Check the box again to stop the flow. Turn the flow valve in Figure 14 90 degrees to isolate the furnace chamber from the atmosphere.

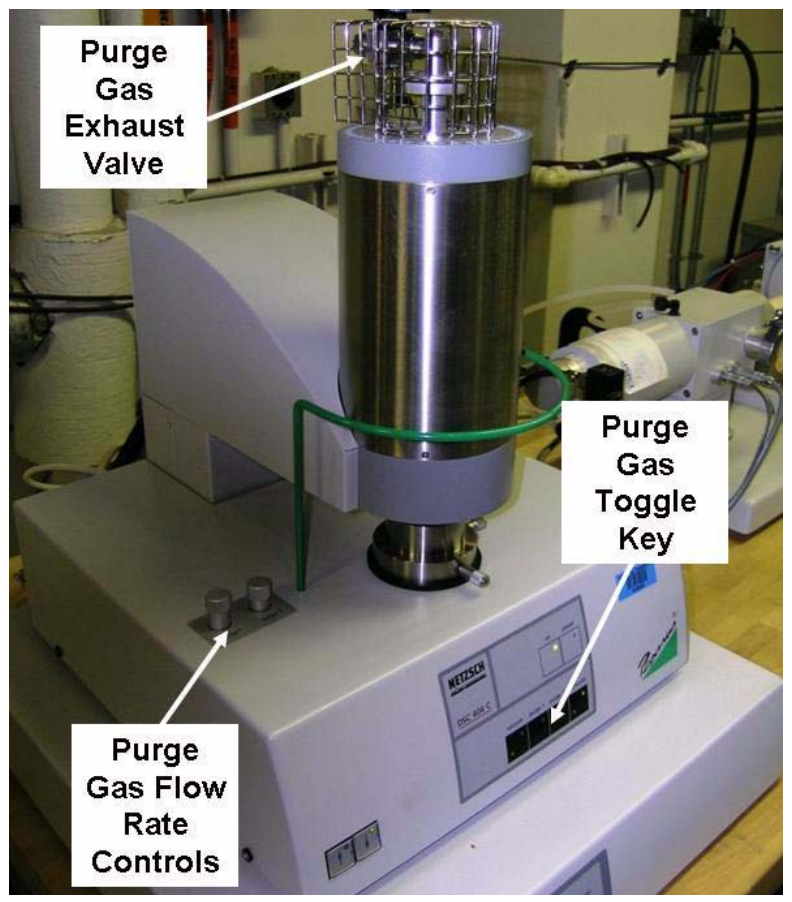

Figure 14. Purge gas controls.

Steps 21-25: Purge the system by switching on the small vacuum pump connected to the system. Slowly open (turn counter clockwise) the valve shown in Figure 10. The pressure reading on the gauge should slowly fall. Once the reading stabilizes, close the vacuum valve and restart purge gas flow using the software. Watch the vacuum gauge. When the gauge reads a pressure of just greater than zero (atmospheric pressure), slowly open the exit valve at the top of the furnace. Repeat the purging cycle twice more.

Step 26: Once the purge has been completed and gas is flowing, press the on-screen "Start" button to begin the test.

Step 27a: Open the Proteus software package. Check the validity of the Baseline by opening the file, also open the most recently used Baseline. If baseline is within 0.2 microvolts of previous acceptable baselines and shows deviation of less than 2.5 microvolts over test it is acceptable. If no previous Baseline data exists, run two Baseline tests and compare these results. If, during the first Baseline test, the signal is rapidly rising or falling (such that the signal drift will exceed 2.5 microvolts), use the micrometers to fine tune the position of the sample carrier for optimum stability. The micrometers are shown in Figure 11. The micrometer at the front of the system should be used for adjustment. Turning the micrometer clockwise will cause the Baseline 


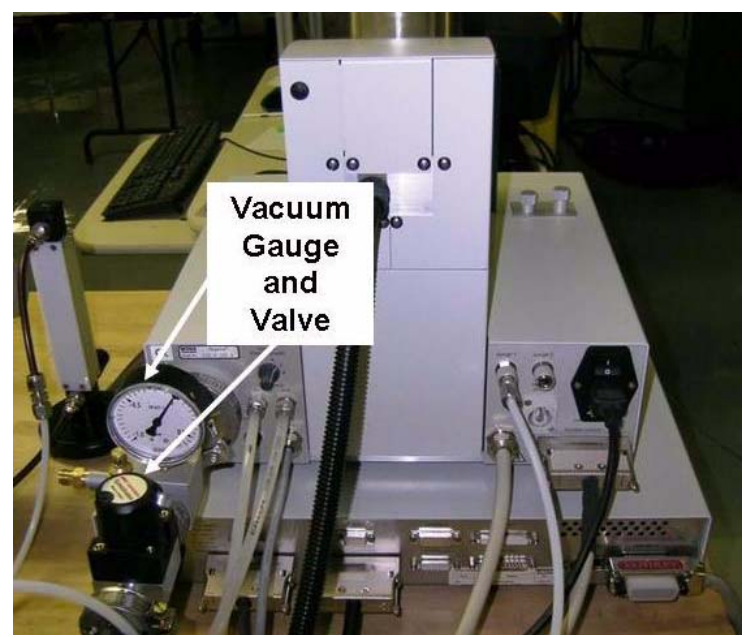

Figure 15. Vacuum valve and gauge behind DSC.

signal to decrease, while turning the micrometer counter clockwise will increase the signal. A clockwise adjustment moves the sample crucible away from the wall (and the heating elements) and the empty (reference) crucible toward the wall. This causes the relative temperature of the sample crucible to drop, decreasing the signal. A counter clockwise adjustment has the inverse effect.

Step 27b: If all three tests have been performed for a sample, the specific heat as a function of temperature may be calculated. Open both "Sample + Correction" files, one for the reference and one for the experimental sample. With both curves visible, select the sample curve to highlight it. From the toolbar, select "Measurement" and choose "Ratio Method" from the drop down menu. A table will appear with the highlighted curve set as the sample, set the reference curve as reference in the table and click "OK." Choose the appropriate reference material file from the folder that opens, this file should match the reference material used (i.e. Sapp for sapphire). The specific heat will be displayed as a new curve.

Step 28b: By selecting "File," "Import Standards," and "Cp" the new specific heat curve may be compared to standard data supplied by the manufacturer.

Step 29: To export data, highlight the desired curve and select "Extras" from the toolbar. Choose "Export To File" from the drop down menu and choose appropriate export options such as data range, export file type, etc. as shown in Figure 16. 


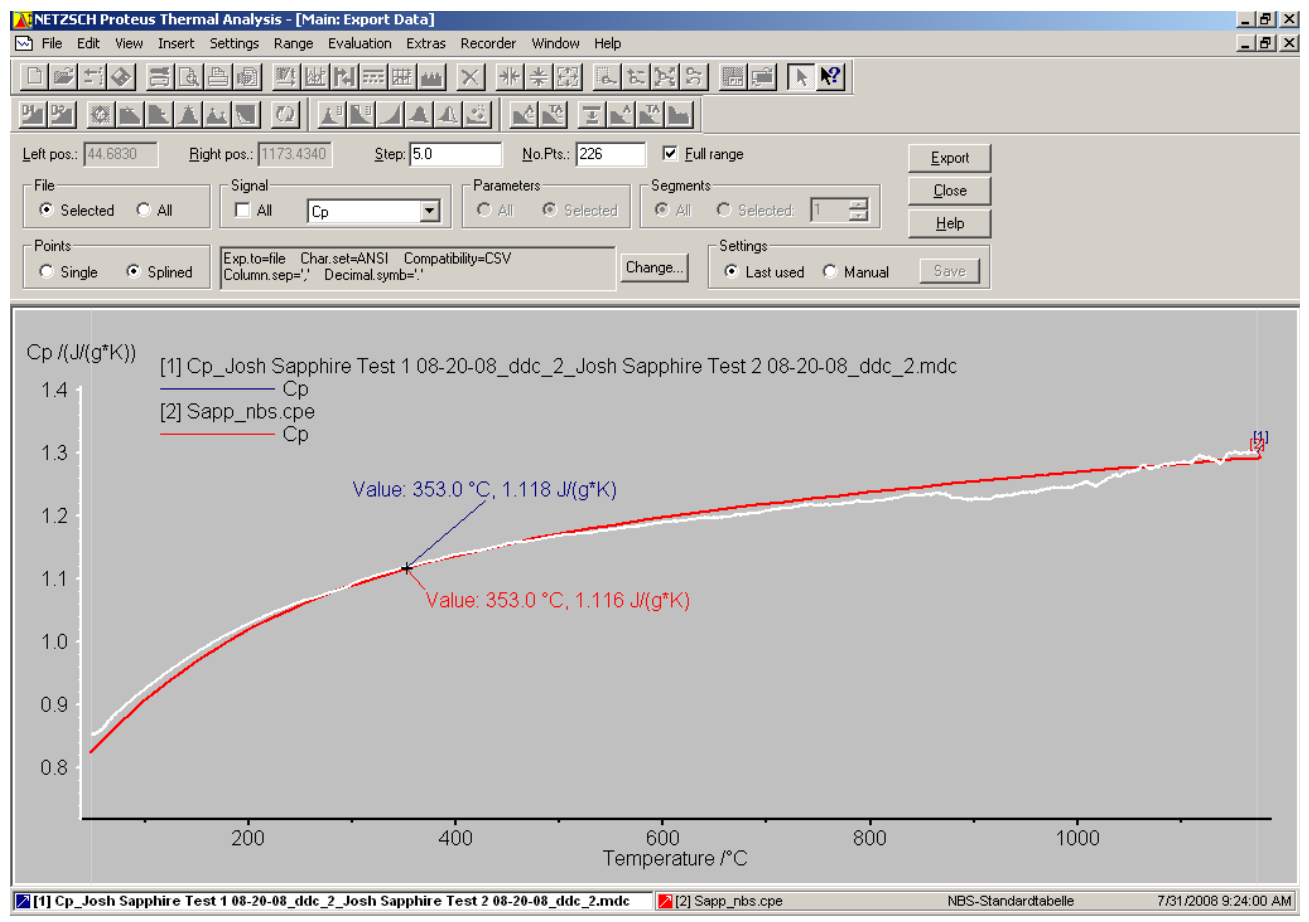

Figure 16. Data export options screen with material standard data curve shown and experimental curve highlighted.

Step 30: Remove sample (if not performing a baseline test) by raising the furnace (only after the furnace has cooled) and gently lifting out the sample crucible. Maintaining the orientation of the crucible (so that it may be replaced into the sample carrier in the same position as before) turn over the crucible such that the lid and sample are both freed from the crucible. Set the crucible down (still maintaining orientation) and, if desired, place a new sample within. After inserting the new sample, if doing so, replace the lid in the same orientation as before removal. Carefully replace the crucible into the sample carrier, in the same position and orientation as in previous tests. Consistency in position and orientation of the crucibles is extremely important for consistent test results.

Step 31: Exit the measurement and analysis programs by closing the program windows.

Steps 32 - 37: Shut down the system by reversing steps 1 through 6. 